\title{
PtAu alloy nanoflowers on 3D porous ionic liquid functionalized graphene-wrapped activated carbon fiber as a flexible microelectrode for near-cell detection of cancer
}

\author{
Lu Wang ${ }^{1}$, Yue Dong ${ }^{2}$, Yan Zhang ${ }^{1}$, Zheye Zhang ${ }^{1}$, Kai Chi ${ }^{1}$, Hao Yuan ${ }^{1}$, Anshun Zhao ${ }^{1}$, Jinghua Ren ${ }^{3}$, \\ Fei Xiao ${ }^{1}$ and Shuai Wang ${ }^{1}$
}

Recent advances in flexible fiber-based microelectrodes have opened a new horizon for sensitive real-time near-cell and even intracellular measurements. In this work, we develop a new type of hierarchical nanohybrid microelectrode based on three-dimensional (3D) porous graphene-wrapped activated carbon fiber (ACF) via a facile and effective electrodeposition of graphene oxide (GO) nanosheets on ACF using a green ionic liquid (IL) as the electrolyte. This technique enables the simultaneous electrodeposition and electrochemical reduction of GO nanosheets on ACF to form 3D porous IL functionalized electrochemically reduced GO (ERGO)-wrapped ACF (IL-ERGO/ACF). The adsorbed IL molecules on the ERGO surface provide sufficient active sites and act as the template for the in situ electrodeposition of highly dense and well-dispersed bimetal PtAu nanoflowers on the 3D IL-ERGO scaffold. By virtue of the unique array of structural and chemical properties of bimetal PtAu nanocatalysts and 3D porous IL-ERGO on ACF, the resultant PtAu nanoflowers-decorated IL-ERGO/ACF (PtAu/IL-ERGO/ACF) microelectrode demonstrates a variety of excellent sensing performances, including high sensitivity, a wide linear range and good selectivity in the electrochemical detection of a newly emerged cancer biomarker, hydrogen peroxide $\left(\mathrm{H}_{2} \mathrm{O}_{2}\right)$. When used for the real-time tracking of $\mathrm{H}_{2} \mathrm{O}_{2}$ secreted from female cancer cells, such as breast cancer cells and gynecological cancer cells, the electrochemical sensor based on the PtAu/IL-ERGO/ACF microelectrode provides important information for distinguishing between different cancer cells and normal cells and for evaluating the therapeutic activity of antitumor drugs towards live cancer cells, which are of great clinical significance for cancer diagnosis and management.

NPG Asia Materials (2016) 8, e337; doi:10.1038/am.2016.189; published online 16 December 2016

\section{INTRODUCTION}

The development of flexible fiber-based electrodes in micro/nanoscale dimensions has attracted tremendous research interest due to the high spatial resolution derived from the reduced geometric area for threedimensionally (3D) addressable local detection in a small volume. ${ }^{1-3}$ In addition, the high temporal resolution for fast electron/mass transfer due to nonplanar diffusion ${ }^{4-6}$ and the intrinsic mechanical and deformational characteristics enable such electrodes to be rolled up and incorporated into compact electrochemical sensor systems. The miniaturized integrated sensor devices based on fiber microelectrodes open the possibility of measuring miniscule body fluid sample volumes for in vitro analysis and minimally invasive in vivo clinical analysis; ${ }^{7-9}$ such devices also provide new insight into near-cell and even intracellular biological signals that can be isolated from the surroundings. ${ }^{10,11}$ Carbon fibers (CFs), as a one-dimension carbon material with a typical diameter of $\sim 5-10 \mu \mathrm{m}$, possess several attractive attributes such as high stiffness and toughness, good elasticity and tensile strength, excellent chemical resistance and temperature tolerance, a low thermal expansion, a light weight and good biocompatibility. These characteristics make CFs an ideal electrode material in microelectrode systems to achieve advances in electrochemistry and biochemistry. ${ }^{12}$ However, the electrochemical activity of bare CF is considerably below the activity required for the ultrasensitive electroanalysis of low-level targets in real samples. Consequently, a great amount of effort has been devoted to the development of effective ways to modify the bare CF electrode by using a variety of functional nanomaterials to improve the sensitivity and precision of bare CF in targeting different types of biomolecules/analytes.

${ }^{1}$ Key Laboratory of Material Chemistry for Energy Conversion and Storage, Ministry of Education, School of Chemistry and Chemical Engineering, Huazhong University of Science and Technology, Wuhan, China; ${ }^{2}$ Britton Chance Center for Biomedical Photonics at Wuhan National Laboratory for Optoelectronics-Hubei Bioinformatics and Molecular Imaging Key Laboratory, Systems Biology Theme, Department of Biomedical Engineering, College of Life Science and Technology, Huazhong University of Science and Technology, Wuhan, China and ${ }^{3}$ Union Hospital, Tongji Medical College, Huazhong University of Science \& Technology, Wuhan, China

Correspondence: Professor F Xiao or Professor S Wang, School of Chemistry and Chemical Engineering, Huazhong University of Science and Technology, \#1037 Luoyu Road, Wuhan 430074, China.

E-mail: xiaofei@hust.edu.cn or chmsamuel@mail.hust.edu.cn

Received 29 June 2016; revised 12 September 2016; accepted 22 October 2016 
As a two-dimensional $\mathrm{sp}^{2}$ carbon nanomaterial, graphene nanosheets have attracted tremendous attention due to their outstanding properties, such as their high theoretical specific area, excellent electric and thermal conductivity and good mechanical strength. ${ }^{13-15}$ Recent studies have demonstrated that graphene nanosheets can be self-assembled into a freestanding 3D interconnected and continuous porous architecture by $\pi-\pi$ interactions between individual graphene nanosheets. ${ }^{16,17}$ The as-obtained graphene assemblies inherit the intrinsic properties of their building block and exhibit exceptional advantages, such as a large surface area, good conductivity, high mechanical flexibility and elasticity under a high tensile strain or large deformation. ${ }^{18,19}$ Furthermore, the as-obtained graphene assemblies can function as ideal carbon substrates for immobilizing noble metal nanostructures, which holds great promise in the development of graphene-based nanohybrid materials with versatile functionality in a wide range of applications. ${ }^{20}$ Taking these characteristics into account, it is anticipated that wrapping bare $\mathrm{CF}$ with $3 \mathrm{D}$ graphene materials will dramatically increase its surface area and roughness factor and facilitate the surface modification of 3D graphene-wrapped CF with a variety of functional groups/nanomaterials. Nevertheless, it remains a challenge to construct a $3 \mathrm{D}$ graphene architecture on a single microscale CF owing to its finite size, smooth surface and insufficient surface active sites. ${ }^{21,22}$ More importantly, the chemical or electrochemical reaction kinetics for assembling 3D graphene materials from their graphene oxide (GO) nanosheets precursor requires high driving forces, which cannot be easily obtained under conventional reaction conditions.

In this work, we present a novel strategy for fabricating 3D porous graphene scaffold-wrapped activated carbon fiber (ACF) via a facile and effective electrodeposition of GO nanosheets on ACF using ionic liquids (ILs) as electrolytes; the material was further modified by highly dense and well-dispersed bimetal PtAu nanoflowers, as shown in Figure 1. Our method to enrich the active sites of ACF for the growth of GO sheets was performed by introducing functional groups such as $-\mathrm{OH}$ and $-\mathrm{COOH}$ onto the fiber surface via the electrochemical oxidation of CF in a mixed solution of pure $\mathrm{H}_{2} \mathrm{SO}_{4}$ and $\mathrm{HNO}_{3}{ }^{23}$ Then, a hydrophilic IL, that is, 1-butyl-3-methylimidazolium tetrafluoroborate $\left([\mathrm{BMIM}]\left[\mathrm{BF}_{4}\right]\right)$, was used to disperse the GO nanosheets and as the electrolyte for the high-efficiency electrodeposition of GO nanosheets on ACF. ILs, which exist in the liquid phase at room temperature and consist entirely of anions and cations, are a highly efficient and green medium for electrochemical applications owing to their unique physicochemical properties, such as their high ionic conductivity, wide potential window, excellent chemical and thermal stability, good solubility and low toxicity. ${ }^{24,25}$ The use of an IL as the electrolyte enables the efficient electrodeposition and electrochemical reduction of GO nanosheets on ACF to form $3 \mathrm{D}$ porous IL functionalized electrochemically reduced GO (ERGO)-wrapped ACF (IL-ERGO/ACF) at a high negative potential of $-2 \mathrm{~V}$; this process cannot be performed using traditional aqueous electrolytes. Furthermore, the IL molecules $[\mathrm{BMIM}]\left[\mathrm{BF}_{4}\right]$ will be adsorbed onto the ERGO sheets via cation- $\pi$ interactions between the imidazolium ring moiety of $[\mathrm{BMIM}]\left[\mathrm{BF}_{4}\right]$ and the $\pi$-electronic surface of ERGO. ${ }^{26}$ The adsorbed IL molecules on the ERGO surface provide sufficient active sites for the nucleation of nanostructured metal materials and act as template to stabilize the materials on the IL-ERGO matrix. Here, bimetal PtAu nanoflowers were grown in situ on the IL-ERGO/ACF electrode by the electrochemical co-deposition of $\mathrm{Pt}$ and $\mathrm{Au}$ from their precursor solutions, which facilitates high loading and good dispersion of the PtAu nanoflowers on the surface of the 3D IL-ERGO scaffold. Moreover, the alloy nanomaterials have a controlled morphology and composition, possess high catalytic activity and an improved durability due to the synergistic effects of the individual functional components, which enhances the current response and improves the stability of the resultant nanohybrid microelectrode.

The practical application of the bimetal PtAu nanoflowersdecorated IL-ERGO/ACF (PtAu/IL-ERGO/ACF) microelectrode was explored in the real-time near-cell-sensitive detection of a cancer biomarker released from live cells. Our findings show that for the electrochemical detection of a newly emerged cancer biomarker, that is, hydrogen peroxide $\left(\mathrm{H}_{2} \mathrm{O}_{2}\right)$, the PtAu/IL-ERGO/ACF microelectrode possesses rapid electron transfer and efficient electrocatalytic properties for the $\mathrm{H}_{2} \mathrm{O}_{2}$ redox reaction, and it can increase the current response as well as lower the $\mathrm{H}_{2} \mathrm{O}_{2}$ redox overpotential. Owing to the synergistic effect at the interface of the bimetal PtAu nanocatalysts, IL molecules and 3D porous ERGO on ACF, the electrochemical $\mathrm{H}_{2} \mathrm{O}_{2}$ sensor based on the PtAu/IL-ERGO/ACF microelectrode exhibits a

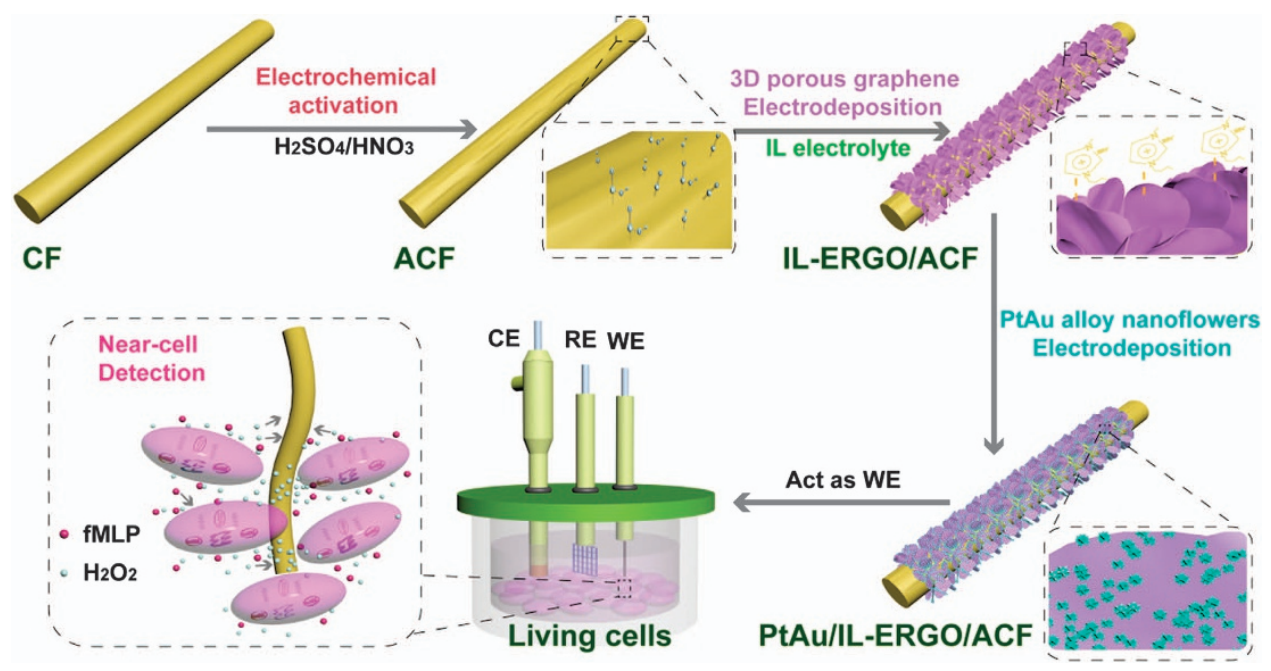

Figure 1 Schematic diagram of the fabrication process for the fiber-based hierarchical nanohybrid microelectrode in a biosensor platform for near-cell cancer detection. ACF, activated CF; CE, counter electrode; CF, carbon fiber; fMLP, N-Formylmethionyl-leucyl-phenylalanine; IL, ionic liquid; RE, reference electrode; WE, working electrode. 
variety of outstanding features, including a high sensitivity of $118 \mu \mathrm{Acm}^{-2} \mathrm{~mm}^{-1}$, a wide linear range from $1.0 \mu \mathrm{M}$ to $19.94 \mathrm{~mm}$, a low detection limit of $1.0 \mu \mathrm{M}$ (a signal-to-noise ratio $\mathrm{S} / \mathrm{N}=3$ ) and good selectivity. When used in the real-time near-cell tracking of $\mathrm{H}_{2} \mathrm{O}_{2}$ secreted from female cancer cells such as breast cancer cells and gynecological cancer cells, the calculated number of extracellular $\mathrm{H}_{2} \mathrm{O}_{2}$ molecules released per cell $\left(N_{\mathrm{o}}\right)$ under the stimulation are $1.69 \times 10^{10}$, $1.98 \times 10^{10}$ and $2.12 \times 10^{10}$ for MDA-MB-231, MCF-7 and Hela, respectively, which are much larger than that of HBL-100 $\left(1.27 \times 10^{10}\right)$. These results confirm that the amounts of $\mathrm{H}_{2} \mathrm{O}_{2}$ released from live cancer cells are much larger than that from a human normal cell line, and the amounts vary for different types of cancer cells. Furthermore, after the cells are treated with DDP, the $N_{\mathrm{o}}$ values for MDA-MB-231, MCF-7 and Hela decrease to $1.36 \times 10^{10}, 1.41 \times 10^{10}$ and $1.83 \times 10^{10}$, respectively, which are 80,71 and $86 \%$ of the $N_{\mathrm{o}}$ values for the untreated cells.

\section{EXPERIMENTAL PROCEDURES}

\section{Synthesis of the PtAu/IL-ERGO/ACF microelectrode}

All reagents were of analytical grade. For the preparation of ACF, single CFs ( $1 \mathrm{~cm}$ in length, $10 \mu \mathrm{m}$ in diameter, from Fuel Cell Earth, USA) were sequentially cleaned by alcohol, acetone and distilled water. The electrochemical activation of the CFs was carried out in a mixture of pure acid solutions of $\mathrm{HNO}_{3}$ and $\mathrm{H}_{2} \mathrm{SO}_{4}$ (volume ratio 1:1, without any purification) under a constant voltage of $3 \mathrm{~V}$ versus saturated calomel electrode (SCE) for $10 \mathrm{~min}$. The as-obtained ACFs were washed by deionized water after the activation process. $^{23}$

The (GO), synthesized from graphite powder (average size of $600 \mathrm{~nm}$ ) by the modified Hummer's method, was mixed with IL $\mathrm{BMIMBF}_{4}$ to obtain a uniform GO-IL suspension and then kept in a vacuum drying oven at $30^{\circ} \mathrm{C}$ for $48 \mathrm{~h}$ to remove the residual water. The electrodeposition of GO nanosheets on ACF was carried out in a standard three-electrode system in the GO-IL suspension $\left(3 \mathrm{mg} \mathrm{ml}^{-1}\right)$ under a constant voltage of $-2 \mathrm{~V}$ versus $\mathrm{Ag} / \mathrm{AgCl}$ for $10 \mathrm{~min}$, with ACF as the working electrode, platinum wire as the counter electrode and silver chloride electrode as the reference electrode, and IL-ERGO/ ACF was obtained.

The electrodeposition of PtAu alloy nanoflowers on IL-ERGO/ACF was performed in $0.5 \mathrm{M} \mathrm{H}_{2} \mathrm{SO}_{4}$ aqueous solution containing $1 \mathrm{mM} \mathrm{H}_{2} \mathrm{PtCl}_{6}$ and $1 \mathrm{mM} \mathrm{HAuCl}_{4}$ at a constant potential of $-0.2 \mathrm{~V}$ versus $\mathrm{Ag} / \mathrm{AgCl}$ for $100 \mathrm{~s}$; the obtained product is denoted as PtAu/IL-ERGO/ACF. For comparison, $\mathrm{Au} / \mathrm{IL}-\mathrm{ERGO} / \mathrm{ACF}$ and Pt/IL-ERGO/ACF were synthesized using the same procedure. All of the modified microelectrodes were washed with distilled water and freeze-dried.

\section{Cell culture}

The human living cells were obtained from the American Type Culture Collection (ATCC, Manassas, VA, USA). The cells were maintained in a culture medium, consisting of Dulbecco's modified minimum essential medium (DMEM, $37^{\circ} \mathrm{C}, 5 \% \mathrm{CO}_{2}$ ) supplemented with $10 \% \mathrm{FBS}, 100 \mathrm{IU} \mathrm{ml}^{-1}$ penicillin and $100 \mathrm{mg} \mathrm{ml}^{-1}$ streptomycin, and subcultured every 3 days. For chemotherapy, the cells were treated with DDP $(0.01 \mathrm{M}, \mathrm{pH} 7.4)$ with a final concentration of $0.2 \mu \mathrm{g} \mathrm{ml}^{-1}$, and after $24 \mathrm{~h}$, serum-free DMEM containing CFSE $(2.5 \mu \mathrm{M})$ was added into each well. The cell numbers were calculated using a cell counter. The cultured living cells were separated from the culture medium by centrifugation for $4 \mathrm{~min}$ at 1500 r.p.m. and washed for three times with physiological PBS (pH 7.4) solution. ${ }^{27}$ The volume of the cell solution was $1.0 \mathrm{ml}$, and the numbers of the different cells were approximately $5.0 \times 10^{6}$. For real-time in situ detection of the $\mathrm{H}_{2} \mathrm{O}_{2}$ released from live cells, the $\mathrm{PtAu} / \mathrm{IL}-\mathrm{ERGO} / \mathrm{ACF}$ microelectrode was carefully placed near the edge of a large amount of live cells using a micromanipulator under a super-resolution digital microscope. The number of extracellular $\mathrm{H}_{2} \mathrm{O}_{2}$ molecules released per cell $\left(N_{\mathrm{o}}\right)$ was calculated according to the following equation: $\left.N_{\mathrm{o}}=\left[(\Delta j / S) \times N_{\mathrm{A}}\right)\right] / N_{\text {cell }}$, where $\Delta j$ is the increase in the amperometric current density of the $\mathrm{H}_{2} \mathrm{O}_{2}$ released from live cells under the stimulation, $S$ is the sensitivity of the proposed nanohybrid microelectrode, $N_{\mathrm{A}}$ is the Avogadro constant $\left(6.02 \times 10^{23} \mathrm{~mole}^{-1}\right)$ and $N_{\text {cell }}$ is the number of cells. ${ }^{28}$

\section{Characterization techniques}

The morphologies and structures of the as-prepared nanohybrid materials were examined by field-emission scanning electron microscopy (SEM, FEI, Nova NanoSEM 450) and transmission electron microscopy (TEM, FEI, Tecnai G220). X-ray photoelectron spectroscopy (XPS) measurements were performed on a Kratos-Axis spectrometer with monochromatic Al-Ka $(1486.71 \mathrm{eV}) \mathrm{X}$-ray radiation $(15 \mathrm{kV}$ and $10 \mathrm{~mA})$ and a hemispherical electron energy analyzer. $\mathrm{X}$-ray diffraction $(\mathrm{XRD})$ patterns were recorded using a diffractometer (X'Pert PRO, Panalytical B.V., Almelo, The Netherlands) equipped with a $\mathrm{Cu}-\mathrm{Ka}$ radiation source $(\lambda=1.5406 \AA)$. The electrochemical performance was evaluated by cyclic voltammetric (CV) and chronoamperometric experiments using a $\mathrm{CHI}$ 660E electrochemical workstation (Shanghai $\mathrm{CH}$ Instruments Co., China). A fluorescence microscope (Olympus BX41F, Osaka, Japan) equipped with a DP73 camera was used to examine the sericin scaffolds under light with different wavelengths. The images were taken with the cellSens standard 1.7 (Olympus) software. A super-resolution digital microscope (VHX-2000) with a micromanipulator was used to place the microelectrode near the edge of the live cells.

\section{RESULTS AND DISCUSSION}

\section{Morphological and structural characterization}

Figure 2a shows the SEM image of a single CF, which has a diameter of approximately $10 \mu \mathrm{m}$ and a smooth surface (Supplementary Material, Supplementary Figures S1a and S1b). The CF material is very stiff, tensile and bendable (Figure $2 \mathrm{a}$ inset), and it can serve as an ideal electrode substrate for flexible microelectrodes. To fabricate the ACF, CF was activated by electrochemical oxidation, which was carried out in a pure acid mixture of $\mathrm{HNO}_{3}-\mathrm{H}_{2} \mathrm{SO}_{4}$ (volume ratio 1:1) under a constant potential of $3 \mathrm{~V}$ for $10 \mathrm{~min}^{23}$ Notably, the smooth surface of ACF becomes relatively rough after electrochemical activation (Figure 2a inset, Supplementary Figures S1c and S1d), which facilitates the electrodeposition of GO nanosheets on the surface. After the electrodeposition of GO nanosheets in the IL electrolyte at $-2 \mathrm{~V}$ versus $\mathrm{Ag} / \mathrm{AgCl}$ for $10 \mathrm{~min}$, the surface of $\mathrm{ACF}$ was entirely covered by a massive $3 \mathrm{D}$ porous graphene layer (Figure $2 \mathrm{~b}$ ) with a uniform thickness of $3 \mu \mathrm{m}$ (Figure $2 \mathrm{~b}$ inset).

The formation mechanism of the $3 \mathrm{D}$ graphene network on ACF during the electrochemical reduction process can be ascribed to the following factors: under a negative applied potential, the electrochemical reduction of GO starts from the surface of the ACF electrode, and the GO nanosheets lose their oxygenated groups (hydroxyl and epoxy groups) and become more hydrophobic; thus, they are deposited onto the electrode substrate due to the strong $\pi-\pi$ stacking interactions and weak electrostatic repulsion. ${ }^{29-31}$ This process can be regarded as a directed growth mechanism, in which the GO nanosheets in the dispersion are enriched on the electrode. ${ }^{29}$ Consequently, we investigated the influence of the GO concentration in the IL solution on the microstructure of the assembled 3D porous graphene layer on the ACF electrode. When the GO concentration in the IL solution is as low as $0.5 \mathrm{mg} \mathrm{ml}^{-1}$, the electrodeposited ERGO layer on the ACF electrode is a loose and disordered film rather than a well-ordered $3 \mathrm{D}$ porous structure due to the inefficient crosslinking of the graphene nanosheets (Supplementary Figure S2a). When the GO concentration in the IL solution increases to $1.0 \mathrm{mg} \mathrm{ml}^{-1}$, the ERGO nanosheets start to prop each other up upon the driving of electric field on the electrode surface to form the 3D IL-graphene network (Supplementary Figure S2b). A further increase of the GO concentration in IL to $3.0 \mathrm{mg} \mathrm{ml}^{-1}$ leads to the construction of a well-defined 3D ERGO architecture on ACF with a continuous microporous 


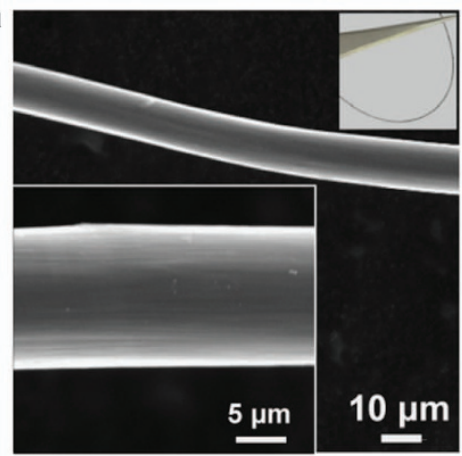

d

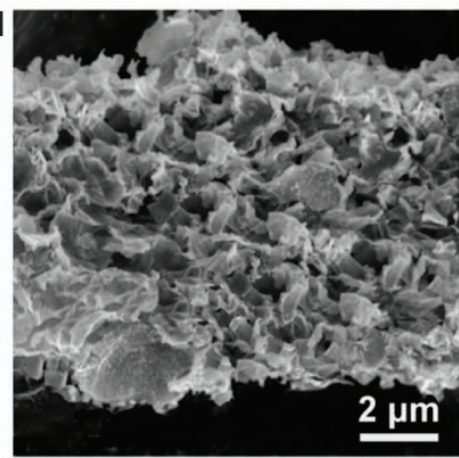

g

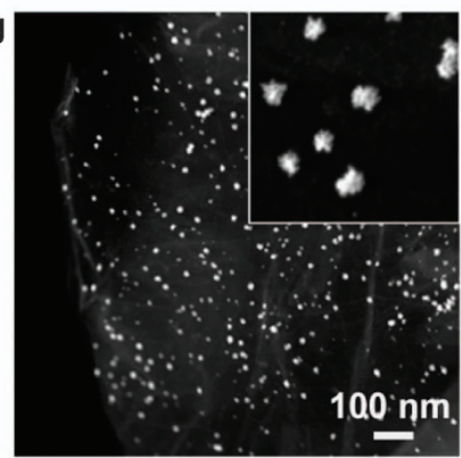

b

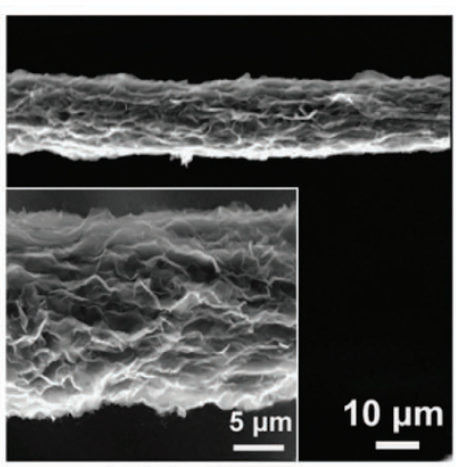

e

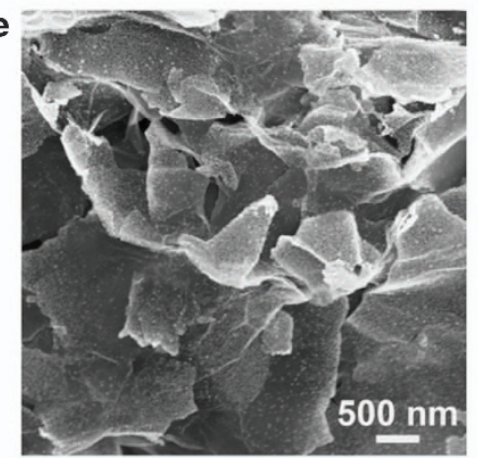

h

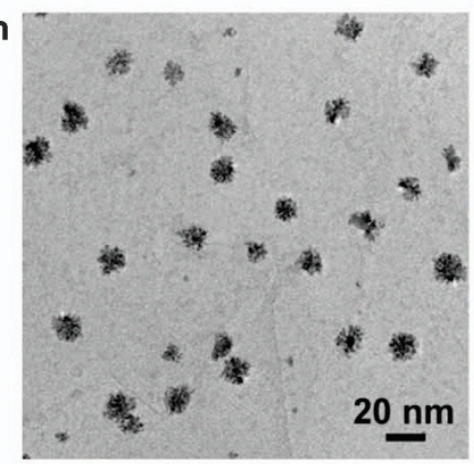

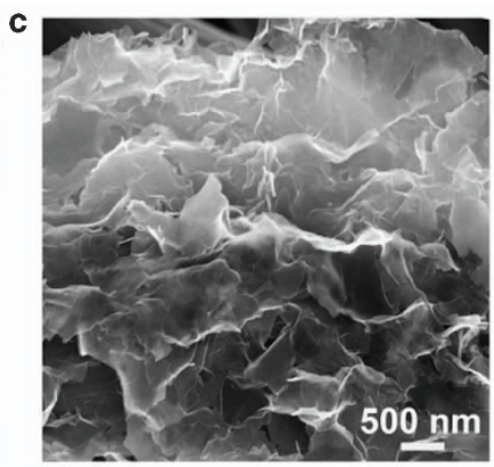
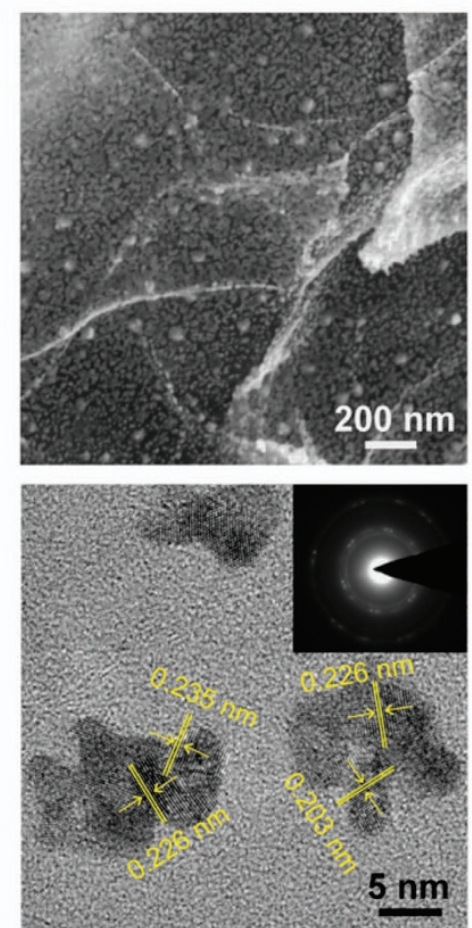
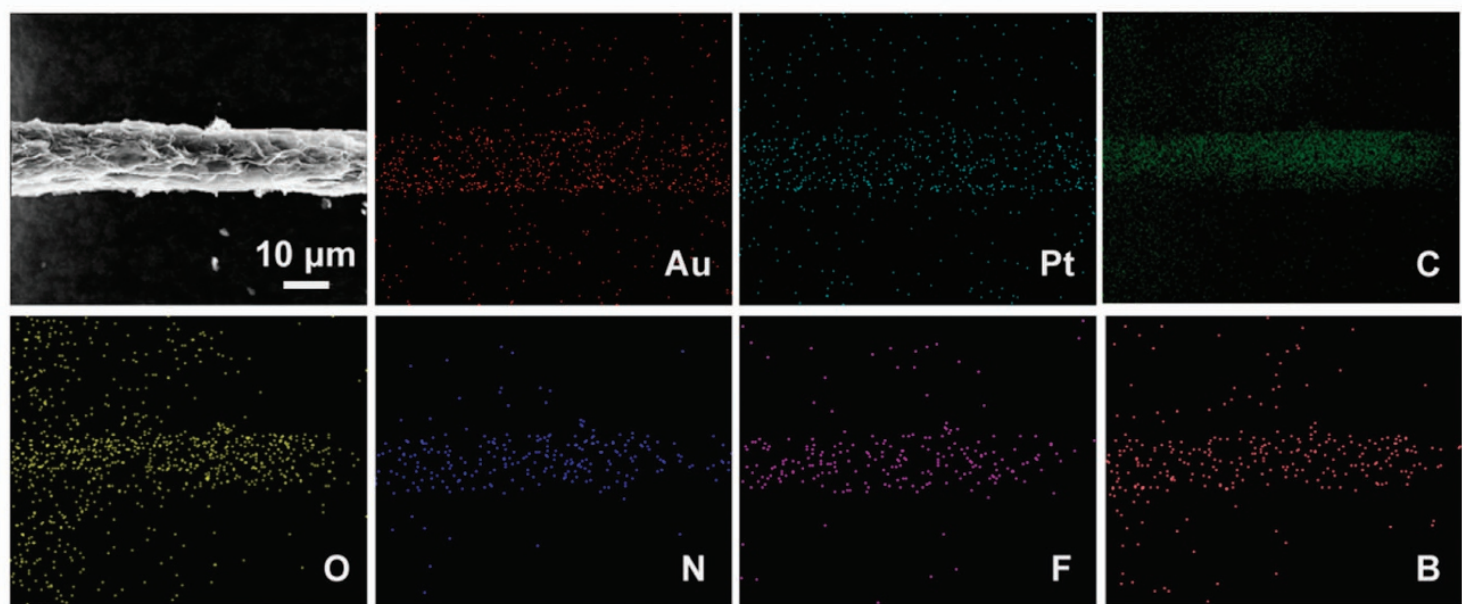

Figure 2 (a) The SEM image of a single CF; the inset is a digital photograph of CF and a higher-magnification image of ACF. (b and c) SEM images of IL-ERGO/ACF under different magnifications. (d-f) SEM images of PtAu/LL-ERGO/ACF under different magnifications. (g) Dark-field TEM image of PtAu/IL-ERGO nanosheets (peeled from the PtAu/IL-ERGO/ACF); the inset is the high-magnification image. (h) TEM and (i) HRTEM images of PtAu alloy nanoflowers on IL-ERGO nanosheets. The inset of $\mathbf{i}$ is the corresponding selected area electron diffraction images (SAED) pattern of the PtAu alloy nanoflowers. (j) SEM elemental mapping images of PtAu/IL-ERGO/ACF. ACF, activated CF; CF, carbon fiber; HRTEM, high-resolution TEM; IL, ionic liquid; TEM, transmission electron microscopy. 
structure, the pore walls consist of thin layers of graphene nanosheets that stand up on ACF, and the pore sizes range from nanometers to several micrometers (Figure 2c).

The composition of the as-prepared $3 \mathrm{D}$ porous IL-graphene materials on ACF was investigated by XRD and EDX. In the XRD pattern, the feature diffraction peak of the GO precursor appears at $10.5^{\circ}$ (Supplementary Figure S3), which corresponds to an interlayer spacing of $0.842 \mathrm{~nm}^{32}$ However, when the GO nanosheets are electrodeposited on ACF, this diffraction peak shifts to $24^{\circ}$, which confirms the effective reduction of GO during the electrodeposition procedure, that is, the formation of ERGO on ACF. EDX spectroscopy indicates the presence of $\mathrm{C}$ and $\mathrm{O}$ elements of graphene and $\mathrm{N}, \mathrm{F}$ and $\mathrm{B}$ elements of IL in the nanohybrid material (Supplementary Figure S4). Therefore, during the electrodeposition of graphene in the IL electrolyte, the IL molecules are grafted onto the graphene nanosheets via the cation $-\pi$ interaction between the imidazolium ring moiety of [BMIM] $\left[\mathrm{BF}_{4}\right]$ and the $\pi$-surface of graphene, which restricts the restacking of graphene nanosheets and promotes the formation of the $3 \mathrm{D}$ graphene network.

Here, bimetal PtAu nanomaterials were grown in situ on the IL-ERGO/ACF electrode by electrochemical co-deposition of Pt and $\mathrm{Au}$ from their precursor solutions to form a $3 \mathrm{D}$ porous nanohybrid material (Figure 2d). During this procedure, the graphene nanosheets are decorated by close-packed PtAu alloy (Figures $2 \mathrm{e}$ and $2 \mathrm{f}$,). Figure $2 \mathrm{~g}$ shows the dark-field SEM images of PtAu/IL-ERGO/ACF, which reveals that the PtAu alloy nanomaterials anchored on the graphene nanosheets have a uniform size and distribution. The microstructure of the PtAu alloy nanomaterials was investigated by high-magnification dark-field (Figure $2 \mathrm{~g}$ inset) and bright-field (Figure 2h) TEM images, which show that the PtAu alloy nanomaterials on the graphene nanosheets exhibit a typical nanoflower structure, and their average size is approximately $10 \mathrm{~nm}$. In addition, the high-resolution TEM (HRTEM) image in Figure $2 \mathrm{i}$ shows that the nanoflowers are an assembly of ultrafine nanoparticles, and the interplanar spacings of $0.235 \mathrm{~nm}, 0.226 \mathrm{~nm}$ and $0.203 \mathrm{~nm}$ in the nanoparticles correspond to lattice planes of $\mathrm{Au}$ (111), Pt (111) and $\mathrm{Au}$ (200), respectively, which indicates that the PtAu nanoflowers actually compose of $\mathrm{Pt}$ and $\mathrm{Au}$ nanoparticles with good crystallinity, as observed in the selected area electron diffraction images (Figure $2 \mathrm{i}$ inset), and an atomic ratio of 17:16 (Supplementary Figure S4). The SEM mapping in Figure 2j illustrates the elemental distribution of $\mathrm{Au}$, $\mathrm{Pt}, \mathrm{C}, \mathrm{O}, \mathrm{N}, \mathrm{F}$ and $\mathrm{B}$ in PtAu/IL-ERGO/ACF, which further indicates the presence of $[\mathrm{BMIM}]\left[\mathrm{BF}_{4}\right]$ and the uniform and intense distribution of PtAu nanoparticles across the entire PtAu/IL-ERGO/ACF surface.

To explore the roles of the IL molecules-grafted ERGO nanosheets in facilitating the electrodeposition of PtAu nanoflowers on IL-ERGO/ACF, the PtAu materials were directly electrodeposited on bare ACF under the same condition. In comparison with that on IL-ERGO/ACF, the PtAu electrodeposited on bare ACF shows a much lower particle density and a larger size ranging from 30 to $70 \mathrm{~nm}$ (Supplementary Figure S5). This phenomenon can be explained as
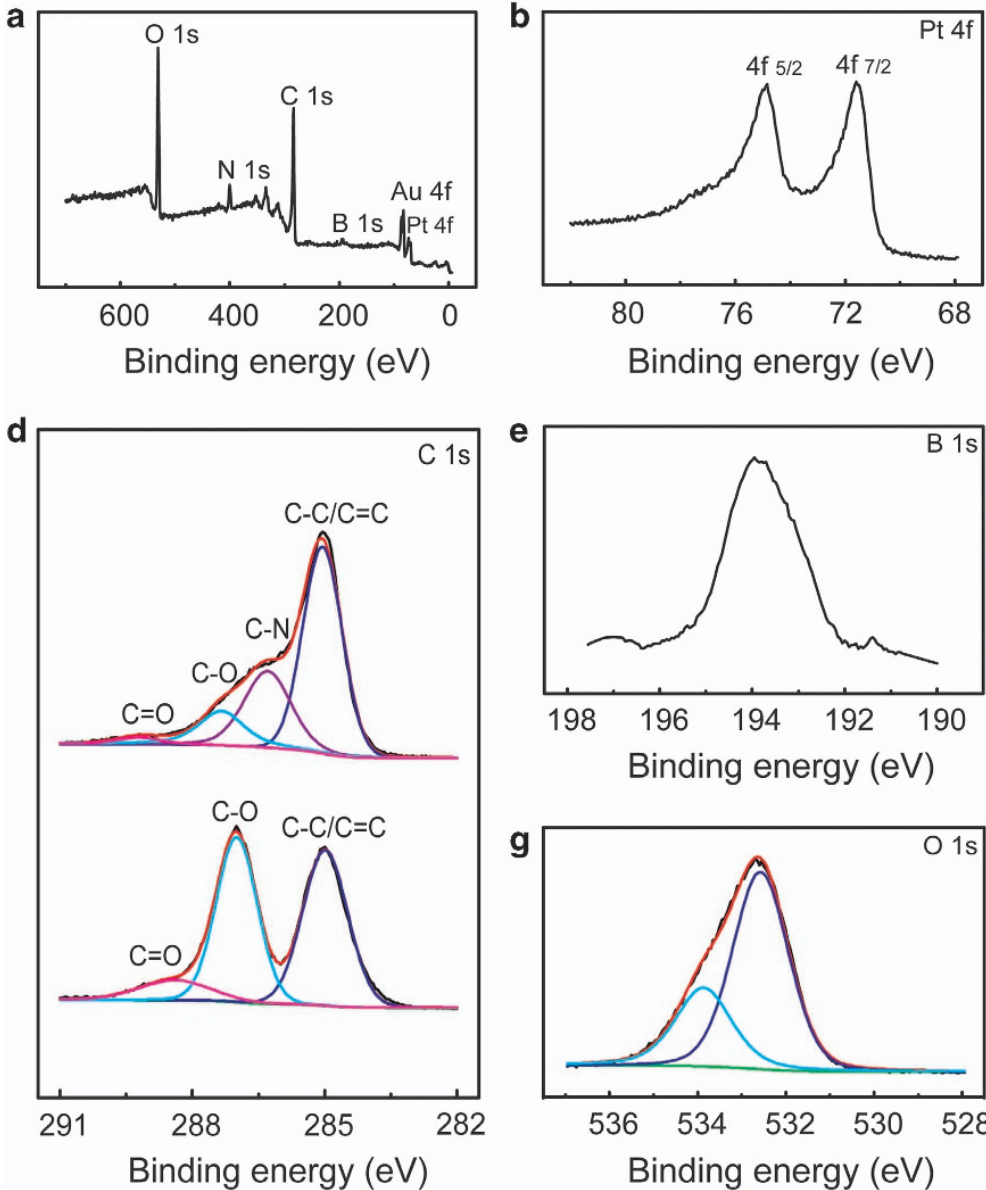
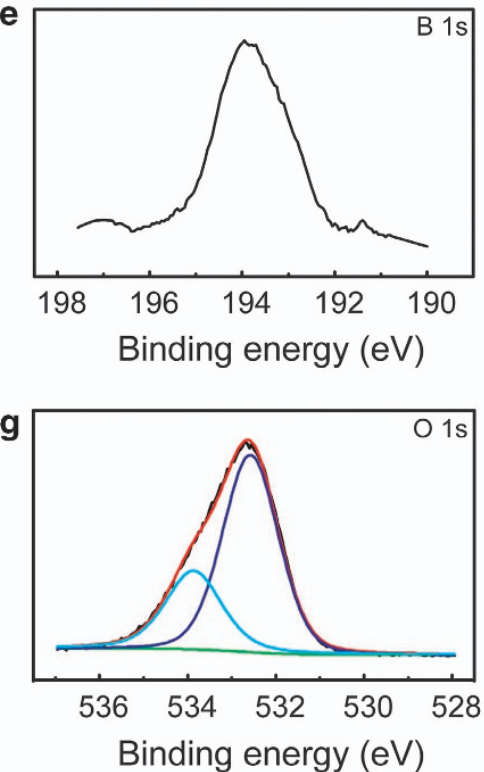
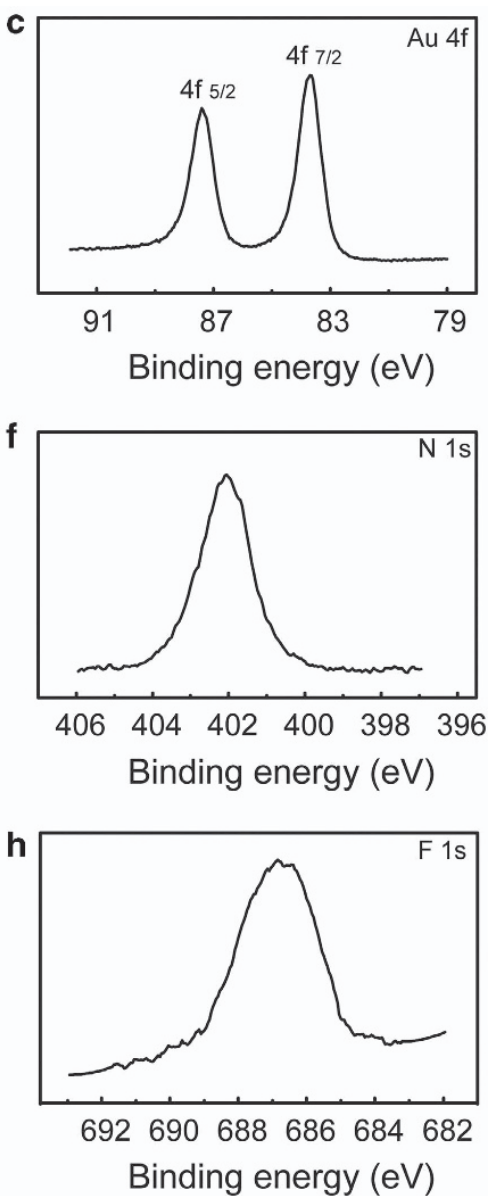

Figure 3 (a) XPS survey spectrum of PtAu/IL-ERGO/ACF. Curve fits of (b) Pt $4 f$, (c) Au $4 f$, (e) B $1 s$, (f) $\mathrm{N} 1 s$, (g) $01 s$ and (h) F $1 s$. (d) C $1 s$ curve fit of PtAu/IL-ERGO/ACF (top) and GO (bottom). ACF, activated CF; CF, carbon fiber; IL, ionic liquid; XPS, X-ray photoelectron spectroscopy. 

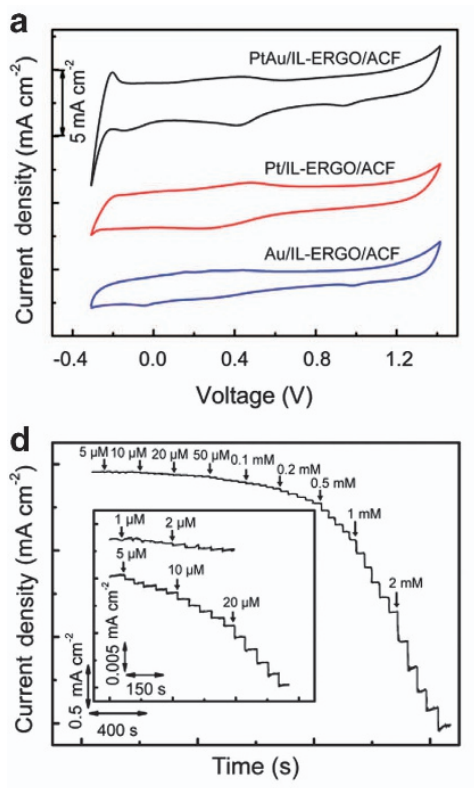
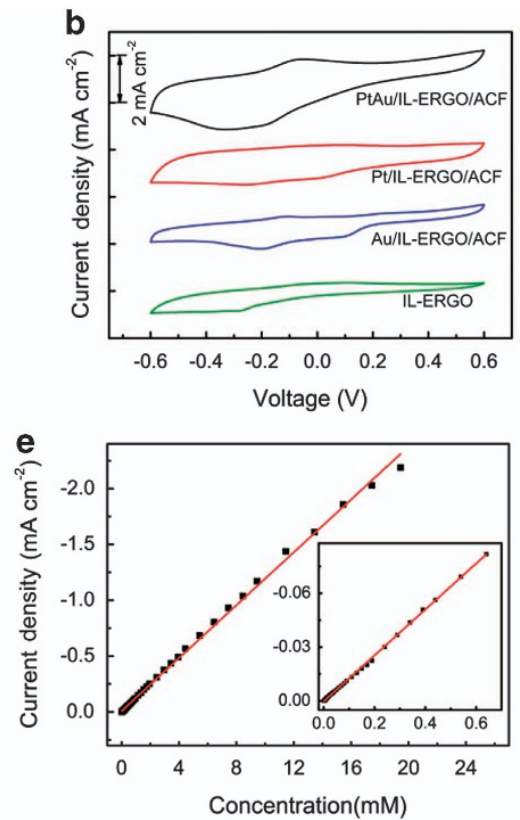

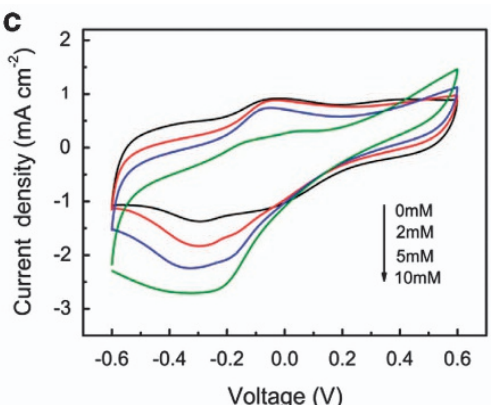

f

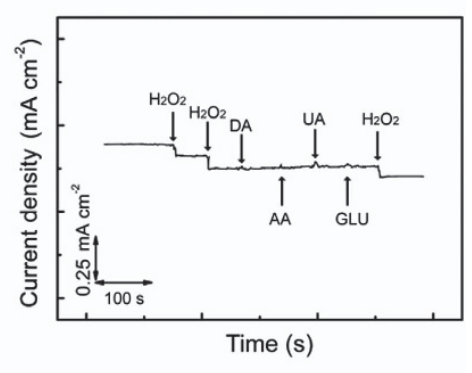

Figure 4 (a) $\mathrm{CV}$ curves of Au/IL-ERGO/ACF, Pt/IL-ERGO/ACF and PtAu/IL-ERGO/ACF microelectrodes in $0.5 \mathrm{M} \mathrm{H}_{2} \mathrm{SO}_{4}$ saturated with nitrogen gas. Scan rate: $50 \mathrm{mV} \mathrm{s}^{-1}$. (b) $\mathrm{CV}$ curves of PtAu/IL-ERGO/ACF, Pt/IL-ERGO/ACF, Au/IL-ERGO/ACF and IL-ERGO/ACF microelectrodes in $0.1 \mathrm{~m}$ PBS solution containing $5 \mathrm{~mm} \mathrm{H}_{2} \mathrm{O}_{2}$ saturated with nitrogen gas. Scan rate: $50 \mathrm{mV} \mathrm{s}^{-1}$. (c) CV curves of PtAu/LL-ERGO/ACF electrode in $0.1 \mathrm{~m} \mathrm{PBS} \mathrm{solution} \mathrm{containing} 0,2,5$ and $10 \mathrm{mM} \mathrm{H}_{2} \mathrm{O}_{2}$ saturated with nitrogen gas. Scan rate: $50 \mathrm{mV} \mathrm{s}^{-1}$. (d) Typical amperometric response of the PtAu/lL-ERGO/ACF microelectrode to the successive addition of different $\mathrm{H}_{2} \mathrm{O}_{2}$ concentrations into $0.1 \mathrm{~m}$ PBS under stirring. The inset represents the amperometric response of the PtAu/lL-ERGO/ ACF electrode at low concentrations. Applied potential: $-0.25 \mathrm{~V}$. (e) The linear relationship between the corresponding current and the $\mathrm{H}_{2} \mathrm{O}_{2}$ concentration. (f) Amperometric response to the successive addition of $0.5 \mathrm{~mm} \mathrm{H}_{2} \mathrm{O}_{2}$ and $0.2 \mathrm{~mm}$ dopamine (DA), ascorbic acid (AA), uric acid (UA) and glucose (GLU) on PtAu/IL-ERGO/ACF at $-0.25 \mathrm{~V}$ in $0.1 \mathrm{~m}$ PBS. ACF, activated CF; CF, carbon fiber; IL, ionic liquid; PBS, phosphate-buffered saline.

follows: ILs with low interfacial tension result in a high nucleation rate, and the $[\mathrm{BMIM}]\left[\mathrm{BF}_{4}\right]$ molecules may act as templates for the formation of nanostructures, such as supramolecular structures formed via hydrogen bonds. ${ }^{33,34}$ Alternatively, the nucleation of PtAu alloy nanoparticles occurs at the dense edge-plane-like defects on ERGO nanosheets, which stabilizes the PtAu alloy nanoparticles on the ERGO scaffold. ${ }^{35,36}$

The surface chemical composition and the electronic interactions of elements in PtAu/IL-ERGO/ACF were further studied by XPS characterization. As shown in Figure 3a, the XPS spectrum of $\mathrm{PtAu} / \mathrm{IL}-\mathrm{ERGO} / \mathrm{ACF}$ exhibits six main peaks assigned to $\mathrm{Pt} 4 f$, $\mathrm{Au}$ $4 f, \mathrm{~B} 1 s, \mathrm{C} 1 s, \mathrm{~N} 1 s$ and $\mathrm{O} 1 s$, which is consistent with the SEM mapping shown in Figure 2j. The corresponding fitted curves of these elements are presented in Figures $3 \mathrm{~b}-\mathrm{h}$. The spectrum of Pt shows a doublet peak located at the binding energies of 71.6 and $74.9 \mathrm{eV}$, which can be assigned to Pt $4 f_{7 / 2}$ and $\mathrm{Pt} 4 f_{5 / 2}$, respectively (Figure $3 \mathrm{~b}$ ), and the peaks at the higher binding energies of 83.65 and $87.35 \mathrm{eV}$ are attributed to $\mathrm{Au} 4 f_{7 / 2}$ and $\mathrm{Au} 4 f_{5 / 2}$, respectively (Figure $3 \mathrm{c}$ ). Compared with the standard XPS spectra of Pt $4 f$ and Au $4 f$ that was previously reported, ${ }^{37}$ the peak of $\mathrm{Pt} 4 f$ in $\mathrm{PtAu} / \mathrm{IL}-\mathrm{ERGO} / \mathrm{ACF}$ shows a blueshift with an enhanced binding energy of $0.4 \mathrm{eV}$, whereas that of $\mathrm{Au} 4 f$ is red-shifted; these results indicate that $\mathrm{Pt}-\mathrm{Au}$ binding occurs during the co-deposition process. This effect may be related to the partial charge transfer from Pt to Au due to the higher electronegativity of the Au element, which leads to the formation of bimetallic PtAu alloy crystals. ${ }^{38}$ The charge transfer from Pt to Au results in the change of the electronic structure and a down-shifting of the $d$-band center of Pt-based alloy materials, which will enhance the adsorption/desorption capability of reaction species on the Pt-based alloy nanocatalyst surface. The surface atom ratio of $\mathrm{Pt} / \mathrm{Au}$ is 19:17 from the XPS analysis, which is roughly in agreement with that obtained by EDX analysis. Figure $3 \mathrm{~d}$ shows the $\mathrm{C} 1 \mathrm{~s}$ core level XPS spectrum of the PtAu/IL-ERGO/ACF and GO samples, both of which exhibit three peaks for the graphitic structure $(\mathrm{C}=\mathrm{C} / \mathrm{C}-\mathrm{C})$, the hydroxyl/epoxy groups $(\mathrm{C}-\mathrm{O})$ and the carbonyl groups $(\mathrm{C}=\mathrm{O})$. However, compared with the $\mathrm{C} 1 s$ XPS spectrum of GO, the peaks for the oxygencontaining groups (that is, $\mathrm{C}-\mathrm{O}$ and $\mathrm{C}=\mathrm{O}$ ) in $\mathrm{PtAu} / \mathrm{IL}-\mathrm{ERGO} / \mathrm{ACF}$ decrease significantly. In addition, the $\mathrm{C}-\mathrm{N}$ assigned to the imidazolium ring moiety of $[\mathrm{BMIM}]\left[\mathrm{BF}_{4}\right]$ is present in the XPS spectrum of PtAu/IL-ERGO/ACF. These results further confirm the successful reduction of GO into ERGO and the grafting of IL molecules onto graphene nanosheets during the electrodeposition procedure.

\section{Electrochemical characterization}

$\mathrm{PtAu} / \mathrm{IL}-\mathrm{ERGO} / \mathrm{ACF}$ was directly used as the working electrode in three-electrode system to evaluate its electrochemical activity. The CV scanning of the PtAu/IL-ERGO/ACF microelectrode was performed in deaerated $0.5 \mathrm{M} \mathrm{H}_{2} \mathrm{SO}_{4}$ solutions in a potential range from -0.3 to $1.4 \mathrm{~V}$, with $\mathrm{Pt} / \mathrm{IL}-\mathrm{ERGO} / \mathrm{ACF}$ and Au/IL-ERGO/ACF as the control electrodes. The oxide formation/reduction peaks of polycrystalline bulk Pt and/or Au are observed for all the nanohybrid microelectrodes. The peaks associated with the reduction of the oxide species at the electrode surface can be used to determine the surface composition of the different nanohybrid microelectrodes. ${ }^{39}$ As observed in Figure $4 \mathrm{a}$, the peak at approximately $1.0 \mathrm{~V}$ is assigned to the $\mathrm{Au}$ species of $\mathrm{Au} / \mathrm{IL}-\mathrm{ERGO} / \mathrm{ACF}$, and the peak at $0.3 \mathrm{~V}$ is associated with the Pt species of Pt/IL-ERGO/ACF. Moreover, the CV curve of $\mathrm{PtAu} / \mathrm{IL}-\mathrm{ERGO} / \mathrm{ACF}$ shows two prominent reduction peaks at $0.5 \mathrm{~V}$ and $0.9 \mathrm{~V}$, which correspond to the $\mathrm{Pt}$ species and $\mathrm{Au}$ species, 
respectively. ${ }^{40}$ The reduction peak of the Pt species is positively shifted by $\sim 200 \mathrm{mV}$, and the reduction peak of the $\mathrm{Au}$ species shifts negatively in contrast to that of $\mathrm{Pt} / \mathrm{IL}-\mathrm{ERGO} / \mathrm{ACF}$ and $\mathrm{Au} / \mathrm{IL}-\mathrm{ERGO} / \mathrm{ACF}$, which is also due to the electronic transfer from $\mathrm{Pt}$ to $\mathrm{Au}$, in agreement with the XPS analysis.

Furthermore, the electrochemically active surface areas (ECSAs) of bare ACF, IL-ERGO/ACF, Au/IL-ERGO/ACF, Pt/IL-ERGO/ACF and $\mathrm{PtAu} / \mathrm{IL}-\mathrm{ERGO} / \mathrm{ACF}$ were estimated using the $\mathrm{Fe}(\mathrm{CN})_{6}{ }^{4-/ 3-}$ redox couple as an electrochemical probe to demonstrate the difference among the these different microelectrodes. The results show that the $\mathrm{CV}$ curves of all the microelectrodes exhibit a pair of well-defined redox peaks that correspond to the quasi-reversible one-electron redox potentials of ferricyanide ion on these electrodes (Supplementary Figure S6). However, the peak potential separation $\left(\Delta E_{\mathrm{p}}\right)$ between the anodic and cathodic peaks is $128 \mathrm{mV}$, and the peak current $\left(i_{\mathrm{p}}\right)$ is relatively small for the bare ACF microelectrode due to its slow charge transfer property and limited ECSA. After the ACF is wrapped by the 3D ERGO material, the resultant ERGO/ACF microelectrode exhibits a reduced $\Delta E_{\mathrm{p}}$ of $86 \mathrm{mV}$ and an enhancement in both the peak current and the current separation between the peak anodic and cathodic currents; this result suggests an improved electron transfer kinetics and increased ECSA and capacitance, which is attributed to the freestanding electrically conductive ERGO sheets on ACF that function as a nanoelectrode array in which the two-dimensional ERGO nanosheets act as individual electrodes to provide necessary conduction pathways. In comparison, the $i_{\mathrm{p}}$ dramatically increases and $\Delta E_{\mathrm{p}}$ decreases for Au/IL-ERGO/ACF, Pt/IL-ERGO/ACF and $\mathrm{PtAu} / \mathrm{IL}-\mathrm{ERGO} / \mathrm{ACF}$, indicating that the highly conductive and electrocatalytically active metal nanoparticles play a vital role in increasing the ECSA and promoting the electron transfer rate. The ECSA values of the different electrodes have been estimated according to the slope of the $i_{\mathrm{p}}$ versus $v^{1 / 2}$ plot based on the Randles-Sevcik equation; ${ }^{41}$ the ECSA values are $0.031 \mathrm{~cm}^{2}, 0.156 \mathrm{~cm}^{2}, 0.315 \mathrm{~cm}^{2}$, $0.368 \mathrm{~cm}^{2}$ and $0.592 \mathrm{~cm}^{2}$ for ACF, IL-ERGO/ACF, Au/IL-ERGO/ ACF, Pt/IL-ERGO/ACF and PtAu/IL-ERGO/ACF, respectively. Evidently, the coating of the $3 \mathrm{D}$ porous IL-ERGO material on ACF dramatically increases the surface area of ACF, and the ECSA value of IL-ERGO/ACF is five times larger than that of bare ACF. Moreover, PtAu/IL-ERGO/ACF exhibits a much larger ECSA value than that of $\mathrm{Au} / \mathrm{IL}-\mathrm{ERGO} / \mathrm{ACF}$ and $\mathrm{Pt} / \mathrm{IL}-\mathrm{ERGO} / \mathrm{ACF}$, which is attributed to the differences in the lattice parameter, crystal structure and nanostructure and the particle dispersion, density and size of the $\mathrm{Pt}, \mathrm{Au}$ and $\mathrm{PtAu}$ alloy nanoparticles obtained by electrodeposition methods. ${ }^{26,33,37}$

The electrocatalytic activity of the PtAu/IL-ERGO/ACF microelectrode towards the $\mathrm{H}_{2} \mathrm{O}_{2}$ redox reaction was further evaluated by $\mathrm{CV}$ measurements. Figure $4 \mathrm{~b}$ shows the $\mathrm{CV}$ curves of $\mathrm{PtAu} / \mathrm{IL}-\mathrm{ERGO} /$ $\mathrm{ACF}$ and those of control electrodes, including Pt/IL-ERGO/ACF, $\mathrm{Au} / \mathrm{IL}-\mathrm{ERGO} / \mathrm{ACF}$ and IL-ERGO/ACF, in $0.1 \mathrm{M}$ phosphate buffer solution (PBS) containing $5 \mathrm{~mm} \mathrm{H}_{2} \mathrm{O}_{2}$. The CV curve of the PtAu/ILERGO/ACF microelectrode exhibits a pair of well-defined redox peaks assigned to the oxidation and reduction of $\mathrm{H}_{2} \mathrm{O}_{2}$ with very low overpotentials, and its peak current densities are the largest among those of all the nanohybrid microelectrodes, which indicates that the $\mathrm{H}_{2} \mathrm{O}_{2}$ redox kinetics is promoted on the surface of the PtAu alloy nanocatalyst. A primary reason for this effect is the larger ECSA value of the PtAu/IL-ERGO/ACF microelectrode, which provides more catalytically active sites and facilitates the electron transfer for the electrochemical redox reaction of $\mathrm{H}_{2} \mathrm{O}_{2}$. Furthermore, as demonstrated by previous reports, several Pt-based alloy nanomaterials, for example, $\mathrm{PtPd},{ }^{42} \mathrm{PtRu},{ }^{43} \mathrm{PtCu}^{44}$ and $\mathrm{PtCo}^{45}$, exhibit enhanced electrocatalytic activity towards the $\mathrm{H}_{2} \mathrm{O}_{2}$ redox reaction in comparison with monometallic Pt nanomaterials. This result is due to the bifunctional effects and electronic modification of the two metallic components in the bimetal alloy. The incorporation of a second metal into Pt will lower the $d$-band center of the Pt-based alloy nanomaterials and reduce the binding energy of intermediate oxygenated adsorbates, which consequently weaken the adsorption ability and lower the activation barriers for the proton- and electron-transfer processes on the alloyed surface; ${ }^{46}$ this favors the $\mathrm{H}_{2} \mathrm{O}_{2}$ redox reaction at low overpotentials.

\section{Electrochemical sensing performance towards $\mathrm{H}_{2} \mathrm{O}_{2}$}

Figure $4 \mathrm{c}$ represents a set of $\mathrm{CV}$ curves of the PtAu/IL-ERGO/ACF microelectrode recorded in PBS containing $\mathrm{H}_{2} \mathrm{O}_{2}$ with different concentrations from $\sim 0-10 \mathrm{~mm}$; the curves exhibit a systematic and dramatic increase of the reduction peak current densities as the $\mathrm{H}_{2} \mathrm{O}_{2}$ concentration increases, indicating that the PtAu/IL-ERGO/ACF microelectrode possesses effective electrocatalytic activity for the reduction of $\mathrm{H}_{2} \mathrm{O}_{2}$. In light of the relationship between the applied potential and the $\mathrm{H}_{2} \mathrm{O}_{2}$ cathode current density, the optimum applied potential for amperometric measurements was selected at $-0.25 \mathrm{~V}$, and the corresponding current-time responses are shown in Figure 4d. On aliquot additions of $\mathrm{H}_{2} \mathrm{O}_{2}$, well-defined steady-state amperometric current responses are obtained within $4 \mathrm{~s}$, and the current densities increase stepwise. As shown in Figure 4e, the electrochemical sensor based on PtAu/IL-ERGO/ACF demonstrates a linear dynamic range over the concentration of $\mathrm{H}_{2} \mathrm{O}_{2}$ from $1.0 \mu \mathrm{M}$ to $19.94 \mathrm{~mm}$, with a high sensitivity of $118 \mu \mathrm{A} \mathrm{cm}^{-2} \mathrm{~mm}^{-1}$ and a detection limit as low as $1.0 \mu \mathrm{M}$ (a signal-to-noise ratio $\mathrm{S} / \mathrm{N}=3$ ), which are comparable and even superior to those of previous works (Supplementary Material, Supplementary Table S1). This result demonstrates the suitability of this system for the highly sensitive and accurate determination of the $\mathrm{H}_{2} \mathrm{O}_{2}$ level released from live cells. The high sensitivity originates from the $3 \mathrm{D}$ porous graphene structure on ACF and the closely packed $\mathrm{PtAu}$ nanoflowers on the graphene nanosheets, which provide abundant nanoscale pores and/or channels that increase the ECSA and facilitate charge transfer and the diffusion of $\mathrm{H}_{2} \mathrm{O}_{2}$ molecules to the electrode; these factors combine to dramatically increase the sensitivity of the amperometric measurement of $\mathrm{H}_{2} \mathrm{O}_{2}$.

To determine the anti-interference ability of PtAu/IL-ERGO/ACF, the influence of some representative electroactive species such as dopamine (DA), ascorbic acid (AA), uric acid (UA) and glucose (GLU) (with a concentration of $0.2 \mathrm{~mm}$ ) on the response of $0.5 \mathrm{~mm}$ $\mathrm{H}_{2} \mathrm{O}_{2}$ was evaluated at an applied potential of $-0.25 \mathrm{~V}$. Owing to the low overpotential of the $\mathrm{H}_{2} \mathrm{O}_{2}$ redox reaction on the PtAu/IL-ERGO/ ACF microelectrode, there were no obvious changes in the current response of $\mathrm{H}_{2} \mathrm{O}_{2}$ after the addition of foreign electroactive species, as observed in Figure $4 \mathrm{f}$, which demonstrates the good selectivity of the $\mathrm{PtAu} / \mathrm{IL}-\mathrm{ERGO} / \mathrm{ACF}$ electrode.

The stability of the proposed flexible PtAu/IL-ERGO/ACF microelectrode with respect to its mechanical stability, repeatability and long-term stability were evaluated in detail. The results show that when the fiber electrode was bent inward to angles of $45^{\circ}, 90^{\circ}, 135^{\circ}$ and $180^{\circ}$, the amperometric response for $0.5 \mathrm{mM} \mathrm{H}_{2} \mathrm{O}_{2}$ changed by $\sim 3.5,4.7,3.8$ and $4.3 \%$, respectively. After the electrode was bent inward to an angle of $180^{\circ}$ for 1 week or upon repetitive bending for 100 times, the retentions of the amperometric current density for $0.5 \mathrm{mM} \mathrm{H} \mathrm{H}_{2} \mathrm{O}_{2}$ are 93.5 and $90.2 \%$, respectively (Supplementary Figure S7). These results collectively indicate that the bendinginduced mechanical stress does not affect the amperometric current response of the PtAu/IL-ERGO/ACF microelectrode. The good 
a

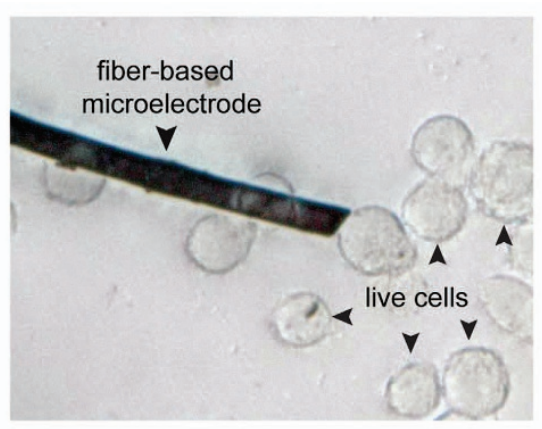

c

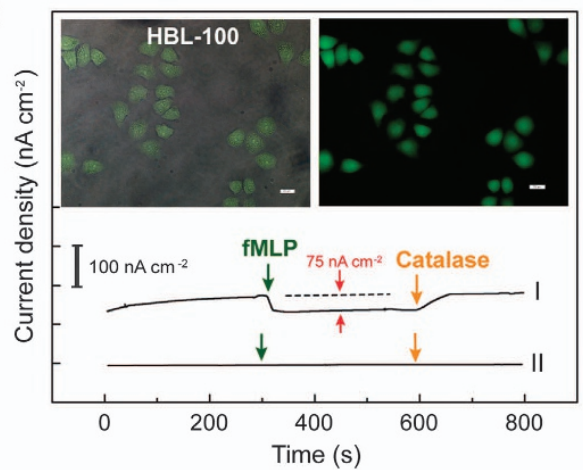

e

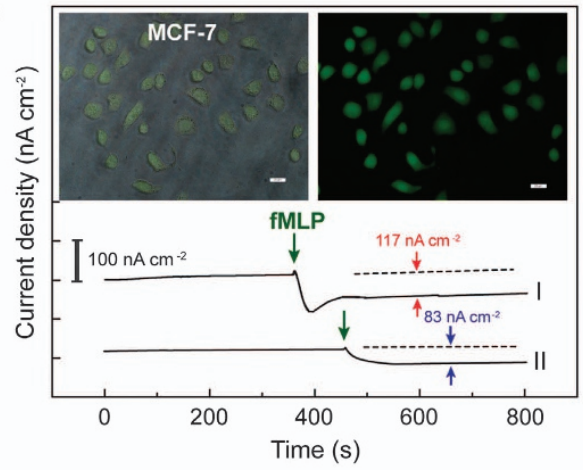

g

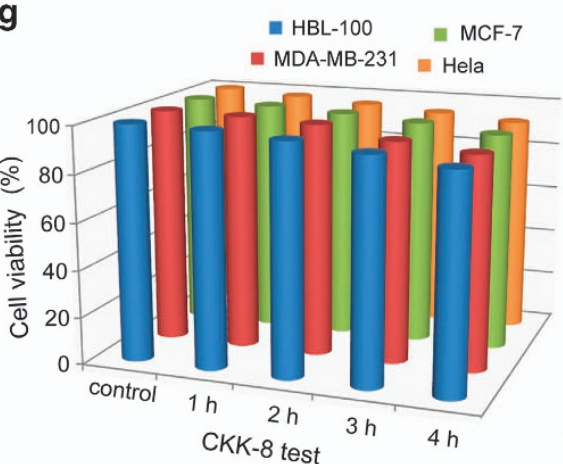

b

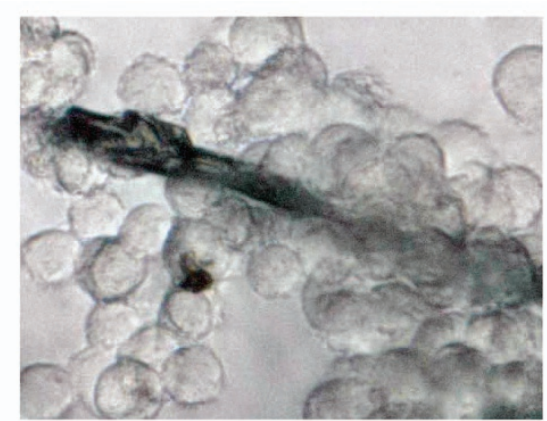

d

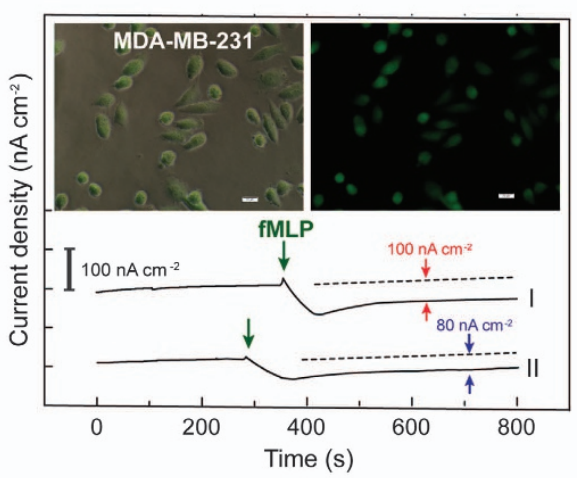

$f$

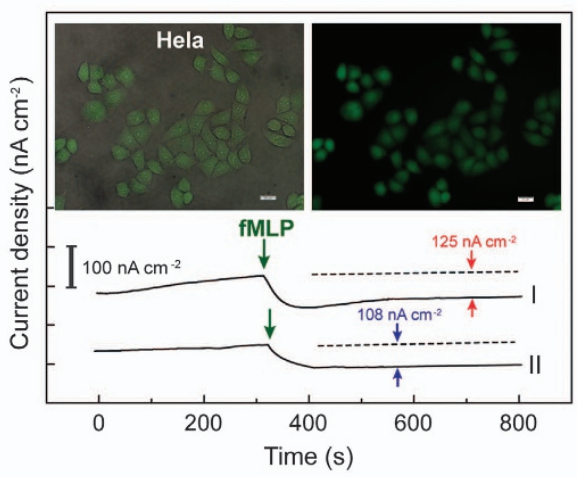

h

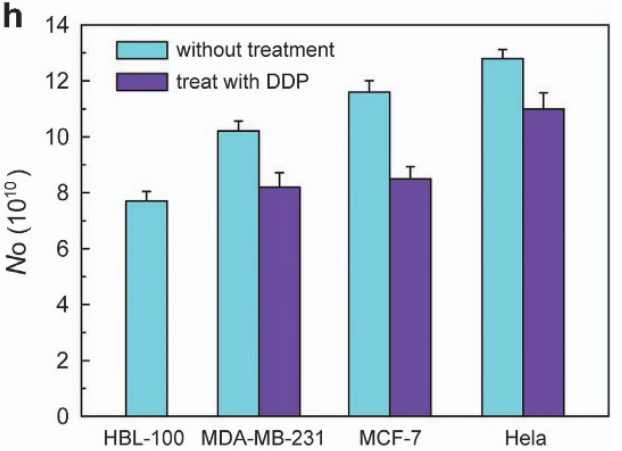

Figure 5 ( $\mathbf{a}$ and $\mathbf{b}$ ) Super-resolution digital microscope images of the PtAu/IL-ERGO/ACF microelectrode during the near-cell monitoring of human live cells. (c) Amperometric current response of the PtAu/LL-ERGO/ACF electrode to the addition of $0.1 \mathrm{~mm} \mathrm{fMLP}$ and $500 \mathrm{U} \mathrm{ml}^{-1}$ catalase in the well containing HBL-100 cells (I) and in the absence of cells (II). Amperometric current response of the PtAu/LL-ERGO/ACF electrode to the addition of $0.1 \mathrm{~mm} f M L P$ in the well containing (d) MDA-MB-231 cells, (e) MCF-7 cells and (f) Hela cells without treatment (I) and after treatment with DDP (II). The insets of c-f are the bright-field and dark-field microscope images of the different live cells. (g) Histograms of the quantitative cell viability of different live cells based on the CCK-8 assay. (h) Histograms of average number of extracellular $\mathrm{H}_{2} \mathrm{O}_{2}$ molecules released per cell $\left(N_{0}\right)$ for different live cells without treatment and after treatment with DDP. ACF, activated CF; CF, carbon fiber; fMLP, N-Formylmethionyl-leucyl-phenylalanine; IL, ionic liquid. 
mechanical stability is due to the high stiffness and toughness of the CF electrode and good adhesion between the PtAu alloy nanoparticles, ERGO nanosheets and CF substrate as a result of electrodeposition; this structure enables the potential for rolling up the electrode into wearable or implantable biomedical devices for in vitro and in vivo measurements.

The repeatability and long-term stability of the PtAu/IL-ERGO/ ACF electrode were evaluated by repeatedly or periodically recording the amperometric current response of one electrode to $0.5 \mathrm{~mm}_{2} \mathrm{O}_{2}$. The results show that the current density retains $\sim 90 \%$ of its initial value after repeated testing for 500 times or storage for 30 days (Supplementary Figure S8), which indicates the good repeatability and long-term stability of the PtAu/IL-ERGO/ACF electrode.

\section{Cancer detection}

Currently, cancer-related diseases have become a leading cause of death on a global scale. Cancer in women, such as breast cancer and gynecological cancer, which develop from the integumentary and reproductive systems, respectively, have become the most widespread forms of cancer that affect women globally. ${ }^{47}$ However, these forms of cancer usually have better prognosis than other types of cancer. If they are diagnosed at early stages and treated by effective methods, patients with these cancers will have a long survival time and experience a high quality of life. Therefore, the early detection of cancers and the assessment of potential therapeutic effects are of great clinical significance and have aroused significant interest from researchers in the development of effective analytical tools for the clinical examination of cancers. Fiber-based sensors represent a new type of flexible microscale device for clinical in vitro and in vivo analysis, and they are relatively suitable for the rapid and accurate quantitative measurement of microliter samples and for near-cell or intracellular detection.

In this work, the proposed PtAu/IL-ERGO/ACF microelectrode was used in the in vitro near-cell detection of the cancer biomarker $\mathrm{H}_{2} \mathrm{O}_{2}$ released from live cancer cells. As one of the primary representative reactive oxygen species, $\mathrm{H}_{2} \mathrm{O}_{2}$ is a significant intracellular signaling molecule due to its association with DNA damage, protein synthesis, cell apoptosis and other cell activities. ${ }^{48} \mathrm{H}_{2} \mathrm{O}_{2}$ has been recognized as an important cancer biomarker, as several investigations have shown that cancer cells usually secrete larger amounts of $\mathrm{H}_{2} \mathrm{O}_{2}$ than their normal counterparts, which is probably due to the rapid uncontrolled growth of cancer cells. Accordingly, the extracellular $\mathrm{H}_{2} \mathrm{O}_{2}$ level provides important information for distinguishing cancer cells from normal cells. Taking all these factors into account, an electrochemicalsensing platform based on the PtAu/IL-ERGO/ACF microelectrode was established for the sensitive detection of the $\mathrm{H}_{2} \mathrm{O}_{2}$ secreted from different types of live cells, that is, normal breast cell HBL-100, the breast cancer cells MDA-MB-231 and MCF-7, and the gynecological cancer cell Hela. Here, the HBL-100 cell is a non-tumorigenic human breast epithelial cell, MDA-MB-231 and MCF-7 are two main types of human breast cancer cell lines, ${ }^{49}$ and Hela cells are cervical cancer cell lines derived from the neck of the womb. For electrochemical testing, the PtAu/IL-ERGO/ACF microelectrode was used as the working electrode, which was put into the test well, carefully moved by a micromanipulator under the microscope from a place containing a few live cells to one with a large amount of cells (Figure 5a), and finally placed near the edge of a large amount of live cells for the in situ sensitive monitoring of $\mathrm{H}_{2} \mathrm{O}_{2}$ released from human cancer cells isolated from their surroundings (Figure 5b). N-Formylmethionylleucyl-phenylalanine (fMLP), a potent polymorphonuclear leucocyte chemotactic factor, has been used as an artificial stimulator to irritate live cells to release ROS. Our findings show that on the addition of
$0.1 \mathrm{~mm}$ fMLP in the test well, a significantly increased amperometric current density of $75 \mathrm{nA} \mathrm{cm}^{-2}$ was obtained in the presence of HBL-100. After the addition of $500 \mathrm{U} \mathrm{ml}^{-1}$ catalase, which is a selective scavenger of $\mathrm{H}_{2} \mathrm{O}_{2}$, the amperometric current response gradually reduced to the background level. In the control test well with no live cells, no electrochemical signals were observed on the addition of either fMLP or catalase (Figure $5 \mathrm{c}$ ). These results indicate that the increased amperometric currents come from the $\mathrm{H}_{2} \mathrm{O}_{2}$ released from live cells under the stimulation.

Furthermore, we calculated the number of extracellular $\mathrm{H}_{2} \mathrm{O}_{2}$ molecules released per cell $\left(N_{\mathrm{o}}\right)$ according to the following equation: $\left.N_{\mathrm{o}}=\left[(\Delta j / S) \times N_{\mathrm{A}}\right)\right] / N_{\text {cell }}$, where $\Delta j$ is the increase in the amperometric current density of $\mathrm{H}_{2} \mathrm{O}_{2}$ released from the live cells under the stimulation, $S$ is the sensitivity of the proposed nanohybrid microelectrode (that is, $118 \mu \mathrm{A} \mathrm{cm}{ }^{-2} \mathrm{~mm}^{-1}$ ), $N_{\mathrm{A}}$ is the Avogadro constant $\left(6.02 \times 10^{23} \mathrm{~mole}^{-1}\right)$, and $N_{\text {cell }}$ is the number of cells $\left(5 \times 10^{6}\right)$. The calculated $N_{\mathrm{o}}$ value is $7.65 \times 10^{10}$ for HBL-100 cell. The repeatability for the near-cell detection of cancer was analyzed using a PtAu/ILERGO/ACF microelectrode for the real-time in situ detection of $\mathrm{H}_{2} \mathrm{O}_{2}$ released in live HBL-100 cells in 10 different testing solutions with the same number of cells. The relative standard deviation of the as-obtained $N_{\mathrm{o}}$ values is less than 5\% (Supplementary Figure S9), which indicates good repeatability of PtAu/IL-ERGO/ACF for the near-cell detection of $\mathrm{H}_{2} \mathrm{O}_{2}$ released from live cells.

The electrochemical signals with respect to the $\mathrm{H}_{2} \mathrm{O}_{2}$ released from live cancer cells were also tracked. As expected, the amperometric current densities for MDA-MB-231, MCF-7 and Hela increased to 100,117 and $125 \mathrm{nA} \mathrm{cm}^{-2}$, respectively (Figures 5d-f). Accordingly, the $N_{\mathrm{o}}$ values are calculated to be $1.02 \times 10^{11}, 1.16 \times 10^{11}$ and $1.28 \times 10^{11}$ for MDA-MB-231, MCF-7 and Hela, respectively, which are roughly consistent with the values obtained from a previous work. ${ }^{28}$ These values are much larger than that of the HBL-100 cell, which confirms that the amounts of $\mathrm{H}_{2} \mathrm{O}_{2}$ released from live cancer cells are much larger than that from the human normal cell line, and they vary for different types of cancer cells. Subsequently, the live cells were treated with cisplatin (DDP), an ultimate cytotoxic agent usually used in clinics to enable tumor resistance. Clearly, after the treatment with DDP, the $N_{\mathrm{o}}$ values for MDA-MB-231, MCF-7 and Hela decrease to $0.82 \times 10^{11}, 0.85 \times 10^{11}$ and $1.1 \times 10^{10}$, respectively, which are 80 , 71 and $86 \%$ of the $N_{\mathrm{o}}$ values for the untreated cells (Figure $5 \mathrm{~h}$ ). This result is because the antitumor drug DDP exhibits a high therapeutic activity against tumors by strongly interacting with nucleobase $\mathrm{N}$-donors of DNA molecules to perturb the tumor structure and inhibit DNA replication. ${ }^{50}$ After undergoing chemotherapy by DDP, the live cancer cells will be killed, and they release less $\mathrm{H}_{2} \mathrm{O}_{2}$ upon stimulation.

The cytotoxicity of PtAu/IL-ERGO/ACF was also investigated, whereby the live cells were incubated with PtAu/IL-ERGO/ACF for a certain period of time. As shown in the bright-field and dark-field fluorescent images in the inset in Figures $5 \mathrm{c}-\mathrm{f}$ inset, all of the live cells remain healthy when they ware incubated with PtAu/IL-ERGO/ACF for more than $4 \mathrm{~h}$. Furthermore, the quantitative analysis of the cell viability using a standard cell counting Kit-8 (CCK-8) assay show that the HBL-100, MDA-MB-231, MCF-7 and Hela cells maintain a viability of greater than $95 \%$ after a $4 \mathrm{~h}$ incubation with PtAu/IL-ERGO/ACF (Figure 5g), indicating the good biocompatibility of PtAu/IL-ERGO/ACF. Therefore, it is highly desirable for exploring its broader application from in vitro to in vivo analysis. 


\section{CONCLUSION}

In summary, we presented a new strategy for preparing a nanohybrid microelectrode by the electrodeposition of 3D porous graphene on ACF using IL as the electrolyte, which was then modified by bimetal PtAu nanoflowers. This system was tested for its practical application in the sensitive near-cell detection of cancer. This strategy has several advantages, including the following: (i) The use of the IL electrolyte enables the efficient electrodeposition and electrochemical reduction of GO nanosheets on ACF to form the 3D porous IL-ERGO supported on ACF, which dramatically increases the surface area and roughness factor of the ACF electrode; (ii) The IL molecules adsorbed on the ERGO surface via cation $-\pi$ interactions promote the in situ growth of PtAu alloy nanoflowers on the surface; (iii) The highloading and well-dispersed bimetal PtAu nanoflowers on the IL-ERGO scaffold possess high electrocatalytic activity, which results in an enhanced current response in the electrochemical detection of $\mathrm{H}_{2} \mathrm{O}_{2}$. As a result, the nanohybrid microelectrode based on $\mathrm{PtAu} / \mathrm{IL}-\mathrm{ERGO} / \mathrm{ACF}$ exhibits good sensing performance, as observed in different tests, and it can be used to evaluate the level of $\mathrm{H}_{2} \mathrm{O}_{2}$ secreted from different female cancer cells in the normal state and after treatment with an antitumor drug. We envision that broader applications of this strategy will contribute to the development of the next generation of minimally invasive implantable devices, compact diagnostic instruments and wearable medical monitoring devices.

\section{Supporting information}

The SEM images of CF, ACF and PtAu/ACF with different magnifications; XRD of IL-ERGO/ACF and GO samples; EDX of PtAu/IL-ERGO/ACF; CV curves of bare ACF, IL-ERGO/ACF, $\mathrm{Au} / \mathrm{IL}-\mathrm{ERGO} / \mathrm{ACF}, \mathrm{Pt} / \mathrm{IL}-\mathrm{ERGO} / \mathrm{ACF}$ and PtAu/IL-ERGO/ACF microelectrodes in $0.1 \mathrm{M} \mathrm{KCl}$ solution containing $1.0 \mathrm{~mm} \mathrm{~K}_{3} \mathrm{Fe}(\mathrm{CN})_{6}$ and $1.0 \mathrm{mM} \mathrm{K}_{4} \mathrm{Fe}(\mathrm{CN})_{6}$. Effects of the bending states on the current responses of the PtAu/IL-ERGO/ACF microelectrode to $0.5 \mathrm{~mm} \mathrm{H}_{2} \mathrm{O}_{2}$; Current responses of one $\mathrm{PtAu} / \mathrm{IL}-\mathrm{ERGO} / \mathrm{ACF}$ microelectrode to $0.5 \mathrm{mM} \mathrm{H}_{2} \mathrm{O}_{2}$ with different storage times and different numbers of repeated tests. Current responses of one PtAu/IL-ERGO/ACF microelectrode for the in situ detection of $\mathrm{H}_{2} \mathrm{O}_{2}$ in 10 different testing solutions with the same number of cells. Table comparing the analytical performance of various nanomaterial-based electrochemical sensors for the detection of $\mathrm{H}_{2} \mathrm{O}_{2}$.

\section{CONFLICT OF INTEREST}

The authors declare no conflict of interest.

\section{ACKNOWLEDGEMENTS}

This research was financially supported by the National Natural Science Foundation of China (Projects No. 51572094 and No. 21305048) and the National Program on Key Basic Research Project (973 Program, Grant No. 2013CBA01600). We thank the Analytical and Testing Center of Huazhong University of Science and Technology for TEM, XPS and XRD characterization.

1 Zeng, W., Shu, L., Li, Q., Chen, S., Wang, F. \& Tao, X. M. Fiber-based wearable electronics: a review of materials, fabrication, devices, and applications. Adv. Mater. 26, 5310-5336 (2014)

2 Wilson, G. S. \& Gifford, R. Biosensors for real-time in vivo measurements. Biosens. Bioelectron. 20, 2388-2403 (2005).

3 Liao, X., Liao, Q., Zhang, Z., Yan, X., Liang, Q., Wang, Q. \& Zhang, Y. A. A highly stretchable Zno@fiber-based multifunctional nanosensor for strain/temperature/uv detection. Adv. Funct. Mater. 26, 3074-3081 (2016).

4 Wei, D., Bailey, M. J., Andrew, P. \& Ryhänen, T. Electrochemical biosensors at the nanoscale. Lab Chip 9, 2123-2131 (2009).
5 Erhard, N., Zenger, S., Morkötter, S., Rudolph, D., Weiss, M., Krenner, H. J. \& Holleitner, A. W. Ultrafast photodetection in the quantum wells of single AIGaAs/GaAsbased nanowires. Nano Lett 15, 6869-6874 (2015).

6 Yang, G., Kampstra, K. L. \& Abidian, M. R. High performance conducting polymer nanofiber biosensors for detection of biomolecules. Adv. Mater. 26, 4954-4960 (2014).

7 Ino, K., Ono, K., Arai, T., Takahashi, Y., Shiku, H. \& Matsue, T. Carbon-Ag/AgCl probes for detection of cell activity in droplets. Anal. Chem. 85, 3832-3835 (2013).

8 Wang, X., Dong, X., Wen, Y., Li, C., Xiong, Q. \& Chen, P. A graphene-cobalt oxide based needle electrode for non-enzymatic glucose detection in micro-droplets. Chem. Commun. 48, 6490-6492 (2012).

9 Gu, S., Lu, Y., Ding, Y., Li, L., Song, H., Wang, J. \& Wu, Q. A. Droplet-based microfluidic electrochemical sensor using platinum-black microelectrode and its application in high sensitive glucose sensing. Biosens. Bioelectron. 55, 106-112 (2014).

10 Xiao, C., Liu, Y. L., Xu, J. Q., Lv, S. W., Guo, S. \& Huang, W. H. Real-time monitoring of $\mathrm{H}_{2} \mathrm{O}_{2}$ release from single cells using nanoporous gold microelectrodes decorated with platinum nanoparticles. Analyst 140, 3753-3758 (2015).

11 Asif, M. H., Ali, S. M. U., Nur, O., Willander, M., Brännmark, C., Strålfors, P. \& Danielsson, B. Functionalised ZnO-nanorod-based selective electrochemical sensor for intracellular glucose. Biosens. Bioelectron. 25, 2205-2211 (2010).

12 Lama, R. D., Charlson, K., Anantharam, A. \& Hashemi, P. Ultrafast detection and quantification of brain signaling molecules with carbon fiber microelectrodes. Anal. Chem. 84, 8096-8101 (2012).

13 Chen, D., Tang, L. \& Li, J. Graphene-based materials in electrochemistry. Chem. Soc. Rev. 39, 3157-3180 (2010).

14 Kim, T., Jung, G., Yoo, S., Suh, K. S. \& Ruoff, R. S. Activated graphene-based carbons as supercapacitor electrodes with macro-and mesopores. ACS Nano 7, 6899-6905 (2013).

15 Xiao, F., Song, J., Gao, H., Zan, X., Xu, R. \& Duan, H. W. Coating graphene paper with 2D-Assembly of electrocatalytic nanoparticles: a modular approach toward highperformance flexible electrodes. ACS Nano 6, 100-110 (2011).

16 Vadivel Murugan, A., Muraliganth, T. \& Manthiram, A. Rapid, facile microwavesolvothermal synthesis of graphene nanosheets and their polyaniline nanocomposites for energy storage. Chem. Mater. 21, 5004-5006 (2009).

17 Cong, H. P., Ren, X. C., Wang, P. \& Yu, S. H. Macroscopic multifunctional graphenebased hydrogels and aerogels by a metal ion induced self-assembly process. ACS Nano 6, 2693-2703 (2012).

18 Zhou, M., Li, X., Wang, B., Zhang, Y., Ning, J., Xiao, Z. \& Zhi, L. High-performance silicon battery anodes enabled by engineering graphene assemblies. Nano Lett. 15, 6222-6228 (2015)

19 Xu, Y., Lin, Z., Huang, X., Liu, Y., Huang, Y. \& Duan, X. Flexible solid-state supercapacitors based on three-dimensional graphene hydrogel films. ACS Nano 7, 4042-4049 (2013).

$20 \mathrm{Xu}, \mathrm{Z}$. \& Gao, C. Graphene in macroscopic order: liquid crystals and wet-spun fibers. Acc. Chem. Res. 47, 1267-1276 (2014).

21 Lugo-Morales, L. Z., Loziuk, P. L., Corder, A. K., Toups, J. V., Roberts, J. G., McCaffrey, K. A. \& Sombers, L. A. Enzyme-modified carbon-fiber microelectrode for the quantification of dynamic fluctuations of nonelectroactive analytes using fast-scan cyclic voltammetry. Anal. Chem. 85, 8780-8786 (2013).

22 Yu, N., Yin, H., Zhang, W., Liu, Y., Tang, Z. \& Zhu, M. Q. High-performance fibershaped all-solid-state asymmetric supercapacitors based on ultrathin $\mathrm{MnO}_{2}$ nanosheet/ carbon fiber cathodes for wearable electronics. Adv. Energy Mater 6 (2016).

23 Wang, W., Liu, W., Zeng, Y., Han, Y., Yu, M., Lu, X. \& Tong, Y. A novel exfoliation strategy to significantly boost the energy storage capability of commercial carbon cloth. Adv. Mater. 27, 3572-3578 (2015).

24 Rogers, R. D. \& Seddon, K. R. Ionic liquids-solvents of the future. Science 302, 792-793 (2003).

25 Zhang, X., Zhang, X., Dong, H., Zhao, Z., Zhang, S. \& Huang, Y. Carbon capture with ionic liquids: overview and progress. Energy Environ. Sci 5, 6668-6681 (2012).

26 Sun, Y. M., Zheng, H., Wang, C., Yang, M., Zhou, A. \& Duan, H. W. Ultrasonic-electrodeposition of PtPd alloy nanoparticles on ionic liquid-functionalized graphene paper: towards a flexible and versatile nanohybrid electrode. Nanoscale $\mathbf{8}$, 1523-1534 (2016)

27 Wang, L., Zhang, Y., Cheng, C., Liu, X., Jiang, H. \& Wang, X. Highly sensitive electrochemical biosensor for evaluation of oxidative stress based on the nanointerface of graphene nanocomposites blended with gold, $\mathrm{Fe}_{3} \mathrm{O}_{4}$, and platinum nanoparticles. ACS Appl. Mater. Interfaces 7, 18441-18449 (2015).

28 Guo, C. X., Zheng, X. T., Lu, Z. S., Lou, X. W. \& Li, C. M. Biointerface by cell growth on layered graphene-artificial peroxidase-protein nanostructure for in situ quantitative molecular detection. Adv. Mater. 22, 5164-5167 (2010).

29 Chen, K., Chen, L., Chen, Y., Bai, H. \& Li, L. Three-dimensional porous graphene-based composite materials: electrochemical synthesis and application. J. Mater. Chem. 22, 20968-20976 (2012).

30 Maiti, U. N., Lim, J., Lee, K. E., Lee, W. J. \& Kim, S. O. Three-dimensional shape engineered, interfacial gelation of reduced graphene oxide for high rate, large capacity supercapacitors. Adv. Mater. 26, 615-619 (2014).

31 Xu, Y., Sheng, K., Li, C. \& Shi, G. Self-assembled graphene hydrogel via a one-step hydrothermal process. ACS Nano 4, 4324-4330 (2010).

32 Jeong, H. K., Lee, Y. P., Lahaye, R. J., Park, M. H., An, K. H., Kim, I. J. \& Lee, Y. H. Evidence of graphitic AB stacking order of graphite oxides. J. Am. Chem. Soc. 130, 1362-1366 (2008). 
33 Xiao, F., Zhao, F., Mei, D., Mo, Z. \& Zeng, B. Nonenzymatic glucose sensor based on ultrasonic-electrodeposition of bimetallic PtM ( $M=R u, P d$ and $A u)$ nanoparticles on carbon nanotubes-ionic liquid composite film. Biosens. Bioelectron. 24, 3481-3486 (2009).

34 Chen, H. \& Dong, S. Self-assembly of ionic liquids-stabilized Pt nanoparticles into two-dimensional patterned nanostructures at the air-water interface. Langmuir 23, 12503-12507 (2007).

35 Jurkschat, K., Wilkins, S. J., Salter, C. J., Leventis, H. C., Wildgoose, G. G., Jiang, L. \& Compton, R. G. Multiwalled carbon nanotubes with molybdenum dioxide nanoplugs-new chemical nanoarchitectures by electrochemical modification. Small 2, 95-98 (2006).

36 Ge, S., Yan, M., Lu, J., Zhang, M., Yu, F., Yu, J. \& Yu, S. Electrochemical biosensor based on graphene oxide-Au nanoclusters composites for I-cysteine analysis. Biosens. Bioelectron. 31, 49-54 (2012).

37 Xiao, F., Mo, Z., Zhao, F. \& Zeng, B. Ultrasonic-electrodeposition of gold-platinum alloy nanoparticles on multi-walled carbon nanotubes-ionic liquid composite film and their electrocatalysis towards the oxidation of nitrite. Electrochem. Commun. 10, 1740-1743 (2008).

38 Zheng, Z., Tachikawa, T. \& Majima, T. Single-particle study of Pt-modified Au nanorods for plasmon-enhanced hydrogen generation in visible to near-infrared region. J. Am. Chem. Soc. 136, 6870-6873 (2014).

39 Zhang, Z. Z., Dong, Y., Wang, L. \& Wang, S. Scalable synthesis of a Pd nanoparticle loaded hierarchically porous graphene network through multiple synergistic interactions. Chem. Commun. 51, 8357-8360 (2015).

40 Zan, X., Fang, Z., Wu, J., Xiao, F., Huo, F. \& Duan, H. W. Freestanding graphene paper decorated with 2D-assembly of Au@Pt nanoparticles as flexible biosensors to monitor live cell secretion of nitric oxide. Biosens. Bioelectron. 49, 71-78 (2013).

41 Bard, A. J., Faulkner, L. R., Leddy, J. \& Zoski, C. G. Electrochemical Methods: Fundamentals and Applications 2, (Wiley, New York, 1980).

$42 \mathrm{Niu}$, X., Chen, C., Zhao, H., Chai, Y. \& Lan, M. Novel snowflake-like Pt-Pd bimetallic clusters on screen-printed gold nanofilm electrode for $\mathrm{H}_{2} \mathrm{O}_{2}$ and glucose sensing. Biosens. Bioelectron. 36, 262-266 (2012).

43 Janyasupab, M., Liu, C. W., Zhang, Y., Wang, K. W. \& Liu, C. C. Bimetallic $\mathrm{Pt}-\mathrm{M}(\mathrm{M}=\mathrm{Cu}, \mathrm{Ni}, \mathrm{Pd}$, and $\mathrm{Rh})$ nanoporous for $\mathrm{H}_{2} \mathrm{O}_{2}$ based amperometric biosensors. Sens. Actuat. B Chem 179, 209-214 (2013).

44 Ensafi, A. A., Abarghoui, M. M. \& Rezaei, B. Facile synthesis of Pt-Cu@silicon nanostructure as a new electrocatalyst supported matrix, electrochemical detection of hydrazine and hydrogen peroxide. Electrochim. Acta 190, 199-207 (2016).

45 Ye, K., Zhang, D., Zhang, H., Cheng, K., Wang, G. \& Cao, D. Platinum-modified cobalt nanosheets supported on three-dimensional carbon sponge as a high-performance catalyst for hydrogen peroxide electroreduction. Electrochim. Acta. 178, 270-279 (2015).

46 Strasser, P., Koh, S., Anniyev, T., Greeley, J., More, K., Yu, C. \& Toney, M. F. Lattice-strain control of the activity in dealloyed core-shell fuel cell catalysts. Nat. Chem 2, 454-460 (2010).

$47 \mathrm{Ma}$, R., Zhang, D., Hu, P. C., Li, Q. \& Lin, C. Y. HOXB7-S3 inhibits the proliferation and invasion of MCF-7 human breast cancer cells. Mol. Med. Rep 12, 4901-4908 (2015).

48 Zhang, Y., Zhang, L. \& Zhou, C. Review of chemical vapor deposition of graphene and related applications. Acc. Chem. Res. 46, 2329-2339 (2013).

49 Liu, T. J., Sun, B. C., Zhao, X. L., Zhao, X. M., Sun, T., Gu, Q. \& Liu, N. CD133+ cells with cancer stem cell characteristics associates with vasculogenic mimicry in triple-negative breast cancer. Oncogene 32, 544-553 (2013).

50 Chen, P., Li, J., Jiang, H. G., Lan, T. \& Chen, Y. C. Curcumin reverses cisplatin resistance in cisplatin-resistant lung cancer cells by inhibiting FA/BRCA pathway. Tumor Biol. 36, 3591-3599 (2015).

(c) (i) This work is licensed under a Creative Commons Attribution 4.0 International License. The images or other third party material in this article are included in the article's Creative Commons license, unless indicated otherwise in the credit line; if the material is not included under the Creative Commons license, users will need to obtain permission from the license holder to reproduce the material. To view a copy of this license, visit http:// creativecommons.org/licenses/by/4.0/

(C) The Author(s) 2016

Supplementary Information accompanies the paper on the NPG Asia Materials website (http://www.nature.com/am) 